rules and regulations. At the same time, digitalization, being a spontaneous and poorly controlled process, carries multiple risks and threats to Russian society. However, the implementation of active measures to legitimize and institutionalize digitalization processes faces a number of problems, from excessive bureaucracy of government instruments to opposition from the network community. The solution to this problem can be the adoption of a new or modification of the existing social contract between public authorities and digital society. This will allow us to consolidate clear frameworks and norms for the use of digital practices, determine the boundaries of what is permissible and, finally, increase the efficiency of the public administration system by unlocking the potential of digitalization. At the same time, the stochasticity and unpredictability of digitalization makes it possible to assert about future, but not manifested yet threats, while a modified social contract can become one of the ways to prevent possible risks.

Keywords: public administration, social and political participation, digitalization, social contract

ВОЕВОДИНА Екатерина Владимировна - кандидат социологических наук, доцент; доцент департамента социологии Финансового университета при Правительстве РФ (125993, Россия, г. Москва, ГСП-3, Ленинградский пр-кт, 49; ekaterinavoevodina@yandex.ru)

\title{
РОЛЬ АКАДЕМИЧЕСКОГО ИНБРИДИНГА В РЕАЛИЗАЦИИ НАУЧНО- ИССЛЕДОВАТЕЛЬСКОГО ПОТЕНЦИАЛА СТУДЕНТОВ ИЗ СОЦИАЛЬНО УЯЗВИМЫХ СЛОЕВ НАСЕЛЕНИЯ
}

Аннотация. В статье раскрываются особенности академического инбридинга, его виды и риски, выявленные российскими и зарубежными исследователями. Предпринята попытка анализа инбридинга с точки зрения реализации «третьей миссии» университетов, в рамках которой предполагается содействие развитию потенциала студентов из социально уязвимых групп населения (прежде всего, имеющих инвалидность, малоимущих). Автор обосновывает принципы модели «здорового» инбридинга, снижающей риски возникновения отрицательных эффектов.

Ключевые слова: академический инбридинг, «третья миссия» университетов, научно-исследовательский потенциал, студент, инвалидность, социально уязвимые группы населения

Q овременное общество подвергается ряду изменений в силу ускорения темпов научно-технологического развития, что сопровождается бурным ростом производства и потребностей населения. Происходит переход к цифровой экономике, влекущей за собой ряд кардинальных изменений в различных областях жизнедеятельности. Все это обостряет вопросы подготовки квалифицированных кадров и неизбежно влечет за собой качественные изменения в вузовской сфере. Задача развития научно-исследовательского потенциала молодежи, выявления и взращивания талантов становится приоритетной целью, обеспечивающей конкурентоспособность эффективной образовательной системы. Руководство университетов заинтересовано в привлечении квалифицированных научно-педагогических кадров, образующих интеллектуальный потенциал вуза, от которого зависит его эффективность и жизнеспособность. Сравнительные исследования образовательных систем Китая, Индии, Бразилии и России показывают, что страны, активно инвестирующие в развитие научно-исследовательского потенциала обучающихся и препода- 
вателей, достигают больших успехов в создании инновационного общества, обладая «прекрасными перспективами развития» [Массовое высшее... 2014: 499]. При этом дискуссионным остается вопрос, как следует «взращивать» интеллектуальный потенциал вуза - за счет собственных студентов, погруженных в университетскую среду со своих первых научных шагов, или сторонних кадров с отличающимся опытом?

Такое явление, как инбридинг - наем университетами своих выпускников, с одной стороны, обладает своими достоинствами. Инбриды более погружены в корпоративную культуру университета, интегрированы в социальную среду; кроме того, при желании вуз может сам моделировать необходимые качества студентов, обеспечивая преемственность научных школ и уникальных практик. С другой стороны, инбридинг все чаще подвергается критике в силу специфических рисков: стагнации развития вуза за счет отсутствия внешнего опыта; своячничества, снижающего здоровую конкуренцию при отборе научно-педагогических кадров; давления авторитета старших сотрудников на инбридов и пр. В данной статье мы проведем анализ положительных и отрицательных эффектов - возможностей и рисков инбридинга, а также попытаемся представить «идеальную» модель «здорового» инбридинга, способствующего росту интеллектуального потенциала университета.

В основу исследования положено понимание научно-исследовательского потенциала студентов как интегральной совокупности когнитивных, мотивационных, поведенческих характеристик личности, обеспечивающих способность эффективного решения исследовательских задач [Берестнева 2015]. Логично предположить, что университеты заинтересованы в первую очередь в инбридах, обладающих наиболее высоким потенциалом. С социологической точки зрения инбридинг - это форма внутриинституциональной мобильности обучающихся, последовательно изменяющих свой статус до уровня преподавателя или исследователя в рамках своей alma mater. В то же время такое определение является упрощенным. Есть несколько подходов к пониманию инбридинга: одни ученые предлагают считать инбридами тех, кто освоил все или почти все уровни образования в вузе, являющимся местом их работы, другие принимают во внимание только ученую степень в университете, считая инбридами всех, кто защитился там, где работает [Altbach, Yudkevich, Rumbley 2015]. До недавнего времени обе практики считались обычными и даже полезными, поскольку за счет инбридов университеты могли обеспечивать преемственность традиций. Наибольшее распространение инбридинг получил в странах Европы и БРИК (Бразилия, Россия, Индия, Китай), кроме того, данная практика характерна для Японии и некоторых старейших университетов Англии и США (к примеру, отделения Гарвардского университета). Однако со временем инбридинг все чаще подвергается критике как в России, так и за рубежом. Некоторые образовательные системы решили законодательно искоренить данную практику: к примеру, в Германии академическая мобильность предполагает, что каждая ступень в карьерной лестнице должна сопровождаться переходом в другой университет: непрерывная карьера внутри одного вуза не просто нежелательна, она считается дурным тоном и всячески пресекается на уровне университетского управления. Исследования в Канаде показывают, что сами сотрудники вузов нередко скептически относятся к инбридингу. Приведем данные опроса 46 преподавателей, представленные Х.Р. Тижушем и Р.Хеммеси [Tizhoosh, Hemmesi 2008]. Так, почти 22\% респондентов (половина из которых сами являются инбридами) отметили, что «наем бывших студентов - это всегда проблема», 56\% выбрали вариант «это может быть проблемой иногда», а $11 \%$ отметили, что это «несерьезная проблема», и никто не выбрал вариант 
о необходимости инбридинга. Краеугольным камнем в критике инбридинга является ограниченность опыта инбридов, а также социальные риски - будь то своячничество или дискриминация.

В публикации М. Солера раскрыты отрицательные эффекты инбридинга, при этом сам автор прибегает в его характеристике к термину «фаворитизм» [Soler 2001]. В коллективной работе Х. Хорты, Ф. Велозо, Р. Гредиага отмечается, что академический инбридинг может «нанести вред ученым» [Horta, Veloso, Grediaga 2010]. Они указывают на то, что инбриды менее продуктивны в публикационной деятельности, чем их «внешние» коллеги, в среднем на 15\%; инбридные университеты замкнуты для остального научного мира - они на $40 \%$ реже обмениваются информацией с внешними коллегами. Российские исследования, при всей их немногочисленности, отчасти поддерживают данный вектор (Е.В. Сивак, М.М. Юдкевич, О.Ю. Горелова). Однако положительные эффекты инбридинга все же отмечаются: так, А.В. Ловаков на основе полевого исследования делает вывод, что инбриды показывают большую приверженность вузу, чем их коллеги с внешним опытом [Ловаков 2015; 123]. Положительный эффект отмечают и китайские исследователи Х. Шэнь, Ч. Сюй, Б. Чжан [Массовое высшее... 2014: 130]. Они указывают на то, что для ведущих вузов, имеющих высокие показатели в рейтингах, инбридинг является типичным явлением и не мешает сохранению их лидерства. Таким образом, инбридинг может положительно сказываться на корпоративной культуре [Академический инбридинг.. 2016: 130]. Обобщая опыт исследований, проанализируем риски и возможности инбридинга в зависимости от наиболее значимых сфер деятельности университета.

1. Научная продуктивность и реализация исследовательского потенциала. Продуктивность ученых сегодня измеряется через ряд наукометрических показателей, влияющих на положение вуза в рейтинге университетов: прежде всего, это число публикаций, цитирований, выигранных конкурсов, грантов. В большинстве исследований отмечается, что инбриды значительно проигрывают по этому показателю в сравнении с «внешними» кадрами. Так, например, в публикациях португальского исследователя Х. Хорты отмечается, что инбриды публикуются меньше и в менее престижных журналах [Horta 2013]. Объяснение этого видится в том, что внешние кандидаты более ориентированы на доказательство своей конкурентоспособности; при трудоустройстве в университет они должны продемонстрировать свои сильные стороны, в то время как инбридов «все уже знают». Кроме того, ученые, ориентированные на инбридинг, нередко имеют только локальные достижения, признаваемые в рамках одного вуза или региона, что, с одной стороны, отражает их сфокусированность на внутриинституциональной системе, а с другой - меньшую внешнюю конкурентоспособность (в т.ч. на глобальном уровне).

2. Включенность в научные сети и обмен информацией. Одним из значительных аргументов против инбридинга является то, что он поощряет внутриакадемическую сегрегацию. Обучение только внутри одного университета исключает возможность развития профессионально значимых связей, затрудняет распространение знаний и, как следствие, выбор лучших практик. В то же время нельзя не отметить, что инбриды более ориентированы на преемственность опыта, традиции научных школ, что обеспечивает сохранение некоторой уникальности, в т.ч. в рамках корпоративной культуры.

3. Социальная адаптация и развитие личностного потенциала. Личностный потенциал является интегральной характеристикой, обобщающей ряд показателей, среди которых для преподавателей и исследователей наиболее существенными являются профессионально значимые качества и компетенции. 
Прежде всего, на эти показатели влияет комфортность социальной среды - тот аспект, где инбриды, казалось бы, должны выигрывать: ведь они со студенческой скамьи интегрированы в систему вуза, а стало быть, их социальная адаптация уже состоялась. Однако большинство исследователей отмечают, что инбриды подвержены дискриминации не меньше, а даже больше их внешних коллег. В первую очередь, это связано с эйджизмом: молодые инбриды нередко оказываются под давлением своих старших коллег, бывших учителей и наставников, что «обязывает» их разделять позицию последних. Не исключены и другие виды дискриминации: к примеру, в Индии это кастовая и языковая дискриминация, при которой доминирующие университетские группы попросту не допускают «чужих» в свои структуры ${ }^{1}$. В целом такие риски типичны для инбридных образовательных систем, характеризующихся прагматическими и приспособительными мотивами среди кадров; цель трудоустройства в вузе в этом случае не связана с реализацией научного потенциала (по крайней мере, не является основной). К примеру, в исследовании М. Сибера, Н. Дебейкер, К. Вандевельд во Фламандском университете (Бельгия) проверялись гипотезы о связи инбридинга и социального статуса. Ученые исходили из допущения, что профессорский корпус представляет замкнутую «олигархию», проявляющую тенденцию к сохранению внутренней однородности путем отбора новых членов, разделяющих схожие ценности и имеющие сходное социальное происхождение [Seeber, Debacker, Vandevelde 2016]. В итоге гипотеза нашла свое подтверждение: замкнутая система, по мнению исследователей, препятствует вовлечению женщин, не инбридных кандидатов и зарубежных преподавателей.

На наш взгляд, обозначенные риски в первую очередь характерны для локальных университетов, слабо вовлеченных в глобальное конкурентное пространство. В то же время можно предположить, что талантливые и заинтересованные кадры будут стараться перейти в более топовые вузы с лучшей ресурсной базой. У таких университетов больше возможностей отбора по принципу «лучший из лучших», в то время как менее именитые вузы будут вынуждены терять талантливых выпускников. Придут ли им на смену выпускники престижных вузов - достаточно спорный вопрос, который зависит от ряда факторов социального характера в каждой стране. Однако настоящая «токсичность» инбридинга будет проявляться, когда вместо таланта при отборе кадров на первое место будут выдвигаться патологичные критерии - фаворитизм, своячничество, локальные достижения, обусловленные административным функционалом инбрида. Опыт Китая показывает, что инбридинг не всегда носит отрицательный характер: он полезен в случае, когда система нуждается в высокообразованных кадрах, которые сама же готовит [Академический инбридинг... 2016: 123]. К тому же сам инбридинг весьма разнообразен. Одна из классификаций инбридов, представленная Х. Хортой, включает:

1) чистых инбридов (pure inbreds), обучавшихся и строивших карьеру в одном и том же вузе;

2) «серебряных академиков» (silver-corded), начавших научную и педагогическую карьеру в «чужом» вузе, а затем вернувшихся в alma mater, в ней же получивших ученую степень;

3) мобильных инбридов (mobile inbreds), успевших освоить внешний опыт путем реализации исследований или преподавания во внешних университетах, прежде чем устроиться на работу в alma mater;

\footnotetext{
${ }^{1}$ Pushkar, Madhvi Gupta. The Menace of Academic Inbreeding Is Ubiquitous. - University World News. The Global Window on Higher Education. 20.07.2017. URL: https://www.universityworldnews. com/post.php?story=20171020151319671 (accessed 26.02.2021).
} 
4) адептов (adherents, noninbreds), характеризующихся однократной мобильностью: сюда относятся те, кто получил ученую степень в вузе, который является его единственным и последним местом работы.

«Серебряные академики» и мобильные инбриды имеют лучшие показатели в работе из-за более разнообразного опыта. В то же время «чистые» инбриды нередко поддерживают саму систему вуза, внося «несоразмерно больший вклад в преподавательскую и научную деятельность и позволяя, таким образом, неинбредным преподавателям посвятить себя исследовательской деятельности» [Horta, Veloso, Grediaga 2010].

Отметим, что академический инбридинг является патологичным в том случае, когда носит внеакадемические мотивы при отборе кадров, где на первое место выступает не талант выпускника, а его социальные связи. Кроме того, «чистый» инбридинг может быть «токсичным» из-за риска необъективной оценки достижений обучающегося - потенциального работника университета в силу других «положительных» личностных качеств (исполнительность, лояльность вузу и пр.). Обзор исследований позволяет заключить, что инбридинг несет в себе риски, когда становится массовой и типичной практикой. Но если посмотреть на этот феномен с другой стороны - с точки зрения системы отбора наиболее талантливых выпускников для работы в своем вузе (которых априори не может быть слишком много), то идея инбридинга не выглядит неудачной. В свете новой тенденции к укреплению социального функционала университетов («третья миссия»), сопряженной с непрерывным образованием, вкладом в развитие человеческих ресурсов, трансфером знаний и пр., рекрутирование талантливой молодежи выглядит социально значимой перспективой, особенно в тех случаях, когда выпускники имеют меньше шансов для мобильности (например, в силу наличия инвалидности). Как отмечают М. Мархл и А. Паусист, «третья миссия» включает в себя не только научно-исследовательскую деятельность, но ориентацию на потребности местного сообщества и участие в социальной жизни [Мархл, Паусист 2013]. С этой позиции инбридинг может рассматриваться как стратегия подготовки кадров с учетом локальных потребностей, где вузы могут способствовать росту «серебряных академиков» из числа талантливых обучающихся.

При этом инбридинг может рассматриваться в рамках социальных программ по развитию потенциала талантливых обучающихся из социально уязвимых групп, под которыми мы понимаем лиц, оказавшихся в трудной жизненной ситуации. В число таких категорий входят маломобильные обучающиеся с инвалидностью, малообеспеченные слои населения, мигранты и пр. Особенностью их социальной уязвимости является необходимость стороннего участия в преодолении ряда барьеров (организационных, социокультурных и пр.). Внося вклад в преодоление этих барьеров за счет внедрения инклюзивных принципов, развивая научно-исследовательский потенциал данных категорий студентов, университет выступает в качестве основного стейкхолдера решения социальных проблем. Анализ опыта российских вузов, занимающихся подготовкой и трудоустройством студентов-инвалидов в рамках своей экосистемы, показывает, что инбридинг может быть эффективной практикой (например, Московский государственный гуманитарно-экономический университет, МГТУ им. Баумана). Однако такие случаи носят единичный характер, а академический инбридинг в целом не рассматривается как возможный инструмент мобильности талантливых обучающихся из социально уязвимых групп населения.

Основной практической проблемой является разработка форм выявления, привлечения (мотивации) кадров, готовых внести вклад в развитие универси- 
тетов - модели «здорового» инбридинга. С учетом обозначенных выше рисков приведем принципы реализации инбридных моделей в рамках социальной миссии университетов.

1. Меритократичность отбора кандидатов, предполагающая, что на место инбрида могут претендовать только те кадры, которые относятся к числу талантливой молодежи. При этом должны учитываться внешние достижения, например, победы в международных, всероссийских, региональных конкурсах вне вуза, в котором обучается кандидат.

2. Многоступенчатый отбор и комплексная оценка достижений, предполагающие, что инбридами могут стать кандидаты, соответствующие ряду разнообразных критериев (академическая успеваемость, победы во внешних конкурсах, публикационная активность и пр.). При этом могут быть использованы различные инструменты: объективные показатели (например, публикационная активность) наряду с качественными методиками оценки (психодиагностика мотивации).

3. Открытость и независимость процедуры отбора: все критерии, этапы отбора в научный кадровый резерв университета должны быть известны стейкхолдерам; к оценке кандидатов должны привлекаться внешние эксперты, в т.ч. из других университетов. Независимая оценка кандидатов должна осуществляться на принципах «слепой» экспертизы там, где это возможно.

4. Раннее выявление и сопровождение талантливой молодежи (с первых курсов обучения), выстраивание образовательной траектории с учетом научно-исследовательских интересов в рамках научных школ, методологических студенческих клубов, семинаров и пр.

Таким образом, мы полагаем, что инбридинг может выступать инструментом развития интеллектуального потенциала вузов в рамках программ социальной ответственности (реализация «третьей миссии»). Однако при реализации инбридных моделей необходимо учитывать существующие риски и тщательно подходить к вопросу кадрового отбора.

В работе отражены результаты прикладного научного исследования по теме «Совершенствование инструментария и разработка предложений по развитию потенциала студенческой молодежс в сфере исследований и разработок» в рамках государственного задания Финансовому университету при Правительстве РФ, 2020 г. (№ ВТК-ГЗ-ПИ-29-20).

\section{Список литературы}

Академический инбридинг и мобильность в высшем образовании. Глобальные nерспективы (под ред. М.М. Юдкевич, Ф.Дж. Альтбаха, Л. Рамбли). 2016. М.: ИД ВШЭ. 328 с.

Берестнева Е.В. 2015. Проблемы оценки исследовательского потенциала. Фундаментальные исследования. № 2(19). С. 4151-4153.

Ловаков А.В. 2015. Приверженность вузу и приверженность профессии у преподавателей российских вузов. - Вопросы образования. № 2. С. 109-128.

Мархл М., Паусист А. 2013. Методология оценки третьей миссии университетов. - Непрерывное образование: ХХІ век. № 1(1). С. 89-101.

Массовое высшее образование: триумф БРИК? (под науч. ред. М.С. Добряковой). 2014. М.: ИД ВШЭ. 525 с.

Altbach Ph., Yudkevich M., Rumbley L. 2015. Academic Inbreeding: Local Challenge, Global Problem. - Asia Pacific Education Review. Vol. 16. No. 3. P. 317-330. 
Horta H. 2013. Deepening Our Understanding of Academic Inbreeding Effects on Research Information Exchange and Scientific Output: New Insights for Academic Based Research. - Higher Education. Vol. 65. No. 4. P. 487-510.

Horta H., Veloso F.M., Grediaga R. 2010. Navel Gazing: Academic Inbreeding and Scientific Productivity. - Management Science. Vol. 56. Is. 3. P. 414-429.

Seeber M., Debacker N., Vandevelde K. 2016. Mobility and Inbreeding in the Heart of Europe. What Factors Predict Academic Career in Dutch-speaking Belgian Universities? - Conference: OECD Blue Sky Forum - towards the next generation of data and indicators. Ghent University. URL: https://www.oecd.org/sti/191\%20 -\%20Mobility\%20and\%20inbreeding\%20in\%20the\%20heart\%20of\%20Europe Seeber\%20Debacker\%20Vandervelde\%20_\%200ECD\%20BLUE\%20SKY.pdf (accessed 26.02.2021).

Soler M. 2001. How Inbreeding Affects Productivity in Europe. - Nature. Vol. 411. P. 132. URL: https://www.nature.com/articles/35075637 (accessed 07.12.2020).

Tizhoosh H., Hemmesi R. 2018. Academic Inbreeding at the Canadian Engineering Schools. - SocArXiv Papers. URL: https://osf.io/preprints/socarxiv/jrk67/ (accessed 26.02.2021).

VOEVODINA Ekaterina Vladimirovna, Cand.Sci. (Soc.), Associate Professor; Associate Professor of the Department of Sociology, Financial University under the Government of the Russian Federation (49 Leningradsky Ave, GSP-3, Moscow, Russia, 1259930; ekaterinavoevodina@yandex.ru)

\title{
THE ROLE OF ACADEMIC INBREEDING IN REALIZING THE RESEARCH POTENTIAL OF STUDENTS FROM SOCIALLY VULNERABLE GROUPS
}

\begin{abstract}
The article analyzes the features of academic inbreeding, its types and risks identified by Russian and foreign researchers (H. Horta, F.M. Veloso, Ph. Altbach, M. Yudkevich, M. Seeber and others). These risks include the poor quality of university research and teaching due to bias in the selection of candidates. Moreover, it depends on the type of academic inbreeding: pure inbreds, silver-corded, mobile inbreds, adherents (noninbreds). In contrast, a model of «healthy» inbreeding of students with high research potential is proposed. The article is based on the concept of the research potential of students as an integral set of cognitive, motivational, behavioral characteristics of a person, providing the ability to solve research problems effectively. Academic inbreeding can be viewed as a tool for implementing the "third mission» of universities and corporate social responsibility programs, within the framework of which it is supposed to promote the development of the potential of students from socially vulnerable groups of the population. The article concludes with general recommendations to stimulate "healthy» academic inbreeding: 1) meritocratic selection of candidates; 2) competitive selection; 3) openness of the selection procedure; 4) comprehensive assessment of achievements; 5) independent evaluation of candidates; 6) early search for talented young researchers using psychological testing and sociological survey methods.
\end{abstract}

Keywords: academic inbreeding, «third mission» of universities, research potential, student, disability, socially vulnerable groups 